
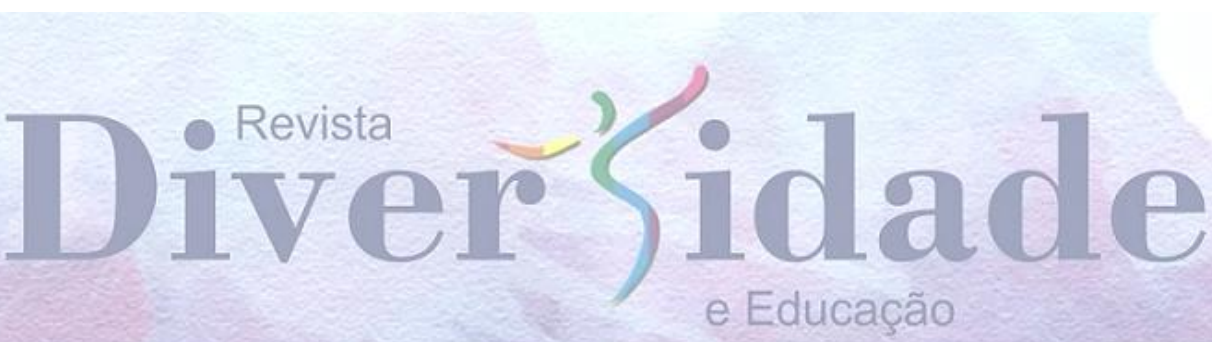

\title{
A DEMOCRATIZAÇÃO DA UNIVERSIDADE E AS POLÍTICAS PÚBLICAS EDUCACIONAIS PARA A DIVERSIDADE SEXUAL NO BRASIL
}

\section{LA DEMOCRATIZACIÓN DE LA UNIVERSIDAD Y LAS POLÍTICAS PUBLICAS EDUCACIONALES PARA LA DIVERSIDAD SEXUAL EN BRASIL}

\author{
THE DEMOCRATIZATION OF THE UNIVERSITY AND PUBLIC \\ EDUCATIONAL POLICIES FOR SEXUAL DIVERSITY IN BRAZIL
}

\author{
Milene Soares Agreli ${ }^{1}$ \\ Maria Alves de Toledo Bruns ${ }^{2}$
}

\section{RESUMO}

Este artigo é uma revisão bibliográfica realizada durante a tese de doutorado A inclusão da diversidade sexual na Universidade, desenvolvida no Programa de Pós-graduação em Psicologia da FFCLRP/USP. Propomos neste artigo um diálogo reflexivo acerca da reivindicação social por democratização do acesso à universidade em interface com as políticas públicas para a diversidade sexual na educação brasileira. Assim, compreendemos que o cenário contemporâneo possibilitou que sujeitos que vivenciam a diversidade sexual passassem a estar presentes nas universidades e reivindicar este espaço de cultura, saber, conhecimento, e também de possibilidade de ascensão social, porém, sem alterar significativamente a profunda desigualdade social brasileira.

PALAVRAS-CHAVE: Diversidade sexual. Educação. Universidade

\section{RESUMEN}

Este artículo es una revisión bibliográfica realizada durante la tesis de doctorado $L a$ inclusión de la diversidad sexual en la Universidad, desarrollada en el Programa de Postgrado en Psicología de la FFCLRP/USP. Proponemos en este artículo un diálogo reflexivo sobre la reivindicación social por democratización del acceso a la universidad en interfaz con las políticas públicas para la diversidad sexual en la educación brasileña. Así, comprendemos que el escenario contemporáneo posibilitó que sujetos que vivencian la diversidad sexual pasas a estar presentes en las universidades y reivindicar este espacio de cultura, saber, conocimiento, y también de posibilidad de ascenso social, pero sin alterar significativamente la profunda desigualdad social brasileña.

PALABRAS-CLAVE: Diversidad sexual. Educación. Universidad.

${ }^{1}$ Doutora pelo Programa de Pós-graduação em Psicologia da Faculdade de Filosofia Ciências e Letras de Ribeirão Preto da Universidade de São Paulo-FFCLRP/USP.

2 Docente e Pesquisadora do Programa de Pós-graduação em Psicologia da Faculdade de Filosofia Ciências e Letras de Ribeirão Preto da Universidade de São Paulo-FFCLRP/USP 


\section{ABSTRACT}

This article is a bibliographical review carried out during the doctoral thesis The inclusion of sexual diversity in the University, developed in the Postgraduate Program in Psychology of the FFCLRP/USP. We propose in this article a reflexive dialogue about the social claim for democratization of access to the university in interface with public policies for sexual diversity in Brazilian education. Thus, we understand that the contemporary scenario made it possible for subjects who experience sexual diversity to be present in the universities and to claim this space of culture, knowledge and the possibility of social ascension, but without significantly altering the profound Brazilian social inequality.

KEYWORDS: Sexual diversity. Education. University

$$
* * *
$$

\section{Introdução}

As experiências de lésbicas, gays, bissexuais, travestis, transexuais e intersexuais (LGBTI) como estudantes universitários/as têm sido uma crescente. No Brasil, alguns estudos revelam que, apesar de todas as adversidades, travestis e transexuais cursaram a universidade e estão exercendo suas funções no mercado de trabalho como docentes (DAVI; BRUNS, 2012, TORRES; PRADO, 2014, SEFFNER; REIDEL, 2015, FRANCO; CICILLINI, 2015).

Com o objetivo de compreender o fenômeno da diversidade sexual no ensino superior brasileiro, realizamos uma revisão bibliográfica durante a tese de doutorado $A$ inclusão da diversidade sexual na Universidade, desenvolvida no Programa de Pósgraduação em Psicologia da FFCLRP/USP, defendida em janeiro de 2018, com apoio CAPES. De tal modo, primeiro discorreremos sobre A reivindicação social por democratização do acesso à universidade, para, em seguida, abordar a relação entre Diversidade sexual, políticas públicas e educação no Brasil tecendo um diálogo reflexivo.

\section{A reinvindicação social por democratização da Universidade}

A estrutura universitária que conhecemos, hoje, no Brasil, é resultado da reforma ocorrida no início dos anos 1970, que se deu mediante uma crise que a universidade enfrentava e que foi disparadora para transformações. 
Segundo Boaventura Sousa Santos (2005) existe uma crise de legitimidade frente à democratização do acesso à universidade justamente quando a reivindicação por acesso à educação superior deixa de ser uma reivindicação utópica, e se torna um movimento de oposição a essa postura elitista da universidade. Cabendo a universidade apenas legitimizar a reivindicação desse movimento e de modo a viabilizar e possibilitar o acesso de todos/as não só aos seus saberes como a produção de saberes que objetivam a melhorar a qualidade da população.

Neste mesmo sentido, para Miguel Rolando Covian (1979), a crise enfrentada pela Universidade está relacionada à busca por legitimidade que se fundamentava na ideia moderna de autonomia e liberdade acadêmica frente ao Estado e à religião, ou seja, a ideia de um conhecimento norteado pela sua própria lógica e por necessidades inerentes. Mas, ao considerar que a universidade é uma instituição social, não se pode entendê-la como um ente independente da sociedade. Ou seja, as modificações na universidade acompanham as transformações sociais, econômicas e políticas refletindo a estrutura e o funcionamento da sociedade como um todo. Portanto, o caráter democrático da universidade pública é determinado pela presença ou ausência da prática democrática do Estado. Logo, a universidade como instituição social autônoma e livre apenas é possível em um Estado democrático.

Atualmente, podemos elencar tentativas da democratização universitária como a Lei de Cotas (Lei n ${ }^{\circ}$ 12.711/2012) que visa a dar condições aos/as estudantes de escolas públicas para ingressarem em Universidades Federais, ao conceder direito a percentual de vagas aos/as estudantes que cursaram todo o ensino médio em escolas públicas. Há também o Programa Universidade para Todos (ProUni), criado pelo Ministério da Educação e regulamentado pela Lei $n^{\circ}$ 11.096/2005, que disponibiliza, aos/as estudantes que completaram o ensino médio, bolsas de estudos integrais e parciais em instituições particulares de ensino superior, em contrapartida à isenção de tributos às instituições participantes do programa. E o Sistema de Seleção Unificada (SISU) em que as instituições públicas de ensino superior (federais ou estaduais) oferecem mais possibilidades aos/as candidatos/as aprovados no Enem, seja através da reserva de vagas propriamente dita, seja através da adoção de bônus na nota de candidatos/as egressos do ensino médio público (Lei de Cotas), ou mesmo através de outro critério de cotas.

Questionamos, então, que o acesso igualitário à universidade não está somente no aumento de vagas para estudantes no nível superior, uma vez que a exclusão iniciase nos graus de ensino fundamental e médio da educação. 
Neste sentido, é claro que as instituições educacionais e as políticas públicas brasileiras precisam ser revistas para não atender à lógica dos olhares excludentes e discriminatórios.

\section{Diversidade sexual, políticas públicas e educação no Brasil}

O espaço escolar brasileiro historicamente vem se constituindo como locus de reprodução das lógicas de exclusão da diversidade sexual, o que causa consequências devastadoras na formação destes sujeitos, como baixa qualidade do ensino, conturbada relação entre docentes e estudantes e evasão escolar. Implicando, ainda, dificuldade de inserção no mercado de trabalho e carreiras profissionais problemáticas de sujeitos LGBTI (JUNQUEIRA, 2009; LIONÇO; DINIZ, 2009).

Segundo dados da UNESCO (2013, p.18), aproximadamente $40 \%$ dos homens homossexuais brasileiros descreveram situações em que foram fisicamente agredidos enquanto frequentavam a escola. A UNESCO define as discriminações decorrentes da orientação sexual e de gênero como "bullyng homofóbico", condição responsável pela perda de oportunidades educacionais e evasão escolar. Já a Associação Brasileira de Lésbicas, Gays, Bissexuais, Travestis e Transexuais - ABGLT afirma que transexuais e travestis são os sujeitos que mais sofrem discriminação na escola, no entanto não existem dados estatísticos oficiais sobre a evasão escolar dos grupos que compõem a diversidade sexual (SOUZA; BERNARDO, 2014).

Dessa forma, o governo federal e de diversos estados brasileiros, perceberam a necessidade de ações urgentes no âmbito do ensino fundamental e médio, ações que acrescentassem, em suas pautas, a questão da vivência escolar de estudantes LGBTI. Um exemplo de ação do governo federal é o programa "Brasil Sem Homofobia" (BRASIL, 2004) que tem por objetivo o fim da violência e a promoção da cidadania LGBTI com enfoque no direito universal de igualdade ao acesso à educação. Mas o que se observa são políticas públicas aplicadas vagarosamente, já que mudanças são um grande desafio às condutas heteronormativas tão cristalizadas na sociedade.

No ano de 2011, também houve a tentativa de serem distribuídos às escolas públicas de todo o Brasil, pelo governo federal, o material contra a homofobia. A grande pressão de setores da sociedade, notoriamente apresentando teores conservadores e moralistas, argumentou que a distribuição do material atuaria como uma "influência negativa" às crianças e adolescentes ao tratar com naturalidade as 
relações homossexuais e as formas de identidade de gênero não normativas. A intensa resistência social às transformações das normas de gênero dominantes culminou no veto e suspensão da distribuição do material (BESAGIO; LARA, 2013).

Da mesma forma, principalmente a partir de 2014, com a aprovação do Plano Nacional de Educação - Lei 13005/2014, os debates sobre gênero e diversidade sexual têm sido frequentes no Congresso Nacional Brasileiro, de forma bastante controversa e com a defesa de posicionamentos opostos, que lançam avanços e retrocessos na conquista de igualdade de direitos ao acesso à educação por parte de estudantes LGBTI.

Se por um lado, uma resolução do Conselho Nacional de Combate à Discriminação e Promoção dos Direitos de Lésbicas, Gays, Bissexuais, Travestis e Transexuais (CNCD/LGBT), órgão vinculado à Secretaria de Direitos Humanos da Presidência da República, publicada no dia 12.03.2015 no "Diário Oficial da União", recomenda que as instituições de educação adotem práticas para respeitar os direitos de estudantes travestis e transexuais, permitindo a estes/as estudantes escolherem quanto ao uso do banheiro - masculino ou feminino - e o tipo de uniforme escolar - masculino ou feminino -, de acordo com a sua identidade de gênero, e, ainda, que tenham o nome social com o qual se identificam inserido em todos os processos administrativos da vida escolar, por outro lado, tramitam no Congresso Nacional, atualmente, dois projetos de lei, inspirados pelo Movimento Escola Sem Partido - que têm o objetivo de afirmar posições, inclusive dentro de sala de aula, para evitar o que denominam "doutrinação política e ideológica”.

Um dos projetos de lei é o 2731/2015 de autoria do deputado federal Eros Biondini (PTB-MG), que altera o Plano Nacional de Educação (PNE), vedando a discussão de gênero dentro das escolas, com a inclusão do seguinte trecho no artigo $2^{\circ}$ do PNE: "É proibida a utilização de qualquer tipo de ideologia na educação nacional, em especial o uso da ideologia de gênero, orientação sexual, identidade de gênero e seus derivados, sob qualquer pretexto". Segundo este projeto de lei os/as professores/as que não atenderem a este dispositivo estarão sujeitos a penas previstas no artigo 232 do Estatuto da Criança e do Adolescente (ECA), que prevê prisão de seis meses a dois anos para aqueles que submeterem "criança ou adolescente sob sua autoridade, guarda ou vigilância a vexame ou constrangimento".

O outro projeto de lei é o 7180/2014 de autoria do deputado federal Erivelton Santana (PEN-BA), que pretende alterar a Lei de Diretrizes e Bases da Educação Nacional (LDBEN), aprovada em 20 de dezembro de 1996, no inciso XIII do artigo $3^{\circ}$, 
para proibir o ensino daquilo que chamam de "ideologia de gênero". Também existem projetos presentes nas elaborações dos Planos Municipais de Educação, que propõem coibir o ensino, nas escolas, daquilo que chamam de "ideologia de gênero" - um slogan ordinariamente reproduzido que acaba por desacreditar os sérios estudos acadêmicos sobre gênero - e outras formas de "ameaças à família e a sociedade".

Pelo viés destes projetos de lei nega-se, aos/às estudantes LGBTI, o espaço necessário da liberdade em sala de aula, o que ratifica os dados de exclusão que se repetem desde o ensino fundamental até o ensino superior.

Tais projetos, se aprovados, corroborarão a tonificação de estigmas como “desviantes" ou "indesejados” aos sujeitos LGBTI presentes nas escolas, e um ambiente escolar hostil impele, seguramente, ao abandono escolar, ainda que, numa inversão de discursos, semeie a ideia de escolha pessoal, dissimulando o fracasso das instituições de ensino ao lidar com as diferenças (ANDRADE, 2015).

Para as universidades, foi lançado o Edital CNPq n. ${ }^{\circ} 45 / 2005$, para apoio e fomentação de projetos de estudos e pesquisas que abordem as temáticas de gênero no país, além do $1^{\circ}$ Prêmio "Construindo a Igualdade de Gênero", com o objetivo de estimular a produção científica e a reflexão acerca das relações e práticas de gênero, e o Encontro Nacional de Núcleos e Grupos de Pesquisa, intitulado "Pensando Gênero e Ciências", realizado em março de 2006, em Brasília. Neste Encontro Nacional, a comunidade acadêmica elaborou algumas propostas em direção ao fortalecimento do campo dos estudos de gênero no país, como: introduzir a disciplina de gênero nos currículos universitários; incluir nos acervos das bibliotecas nacionais publicações no campo de estudos de gênero e diversidade sexual; estimular e apoiar os Núcleos e Grupos de Estudos sobre gênero nas Universidades, e incentivar e fortalecer os cursos de pós-graduação em questão de gênero nas Universidades Públicas (NARVAZ; KOLLER, 2007).

Atualmente, diversos conselhos universitários por todo o Brasil aprovaram o uso do nome social para estudantes e servidores/as travestis e transexuais, com a mudança de todos os documentos institucionais, bem como aprovaram o uso do banheiro, conforme a identidade de gênero.

\section{Considerações Finais}


As tentativas de democratização de acesso à universidade para a diversidade sexual no Brasil demonstra-se frágil e superficial, já que não alteraram significativamente os padrões de desigualdade social, continuam promovendo diferenças de oportunidade e criando um "círculo vicioso", o que aponta para uma imobilidade social.

É imperativo o desenvolvimento de estratégias educativas, desde os primeiros anos escolares, adequadas à diversidade sexual e de gênero, por meio de práticas de ensino inclusivas que garantam uma aprendizagem bem sucedida à todos/as estudantes.

\section{Referências}

ANDRADE, Luma Nogueira. Travestis na escola: Assujeitamento e resistência à ordem normativa. São Paulo: Metanoia Editora, 2015.

BESAGIO, Natália Martins; LARA, Renata Marcelle. A educação no espaço digital: Kit anti-homofobia e os efeitos de sentido no discurso midiático. Anais do IV Congresso Nacional de Linguagens em Interação Múltiplos olhares, Maringá, 2013.

BRASIL. LEI N ${ }^{\circ}$ 13.005, DE 25 DE JUNHO DE 2014. Aprova o Plano Nacional de Educação - PNE e dá outras providências. Brasília, DF, 2014. Disponível em: http://www.planalto.gov.br/ccivil_03/_Ato2011-2014/2014/Lei/L13005.htm Acesso em: 12 out 2016.

BRASIL. LEI N ${ }^{\circ}$ 12.711, DE 29 DE AGOSTO DE 2012. Dispõe sobre o ingresso nas universidades federais e nas instituições federais de ensino técnico de nível médio e dá outras providências, Brasília, DF, 2012. Disponível em: http://www2.camara.leg.br/legin/fed/lei/2012/lei-12711-29-agosto-2012-774113publicacaooriginal-137498-pl.html Acesso em: 12 out 2016.

BRASIL. LEI N ${ }^{\circ}$ 11.096, DE 13 DE JANEIRO DE 2005. Institui o Programa Universidade para Todos - PROUNI, regula a atuação de entidades beneficentes de assistência social no ensino superior; altera a Lei $n^{0} 10.891$, de 9 de julho de 2004, e dá outras providências. Brasília, DF, 2005. Disponível em: http://www.planalto.gov.br/ccivil_03/_Ato2004-2006/2005/Lei/L11096.htm Acesso em: 12 out 2016.

BRASIL. PROJETO DE LEI No 2731, DE 2015. Altera a Lei $n^{\circ} 13.005$, de 25 de junho de 2014, que estabelece o Plano Nacional de Educação - PNE e dá outras providências. Brasília, DF, 2015. Disponível em: http://www.camara.gov.br/proposicoesWeb/ prop_mostrarintegra;jsessionid=7ECE062FD9A8874577008B481B4577FE.proposicoes Web1 ?codteor $=1380897 \&$ filename=Avulso+-PL+2731/2015. Acesso em: 12 out 2016.

BRASIL. PROJETO DE LEI No 7.180, DE 2014. COMISSÃO ESPECIAL ESCOLA SEM PARTIDO. Brasília, DF, 2014. Disponível em: 
https://www.camara.gov.br/proposicoesWeb/prop_mostrarintegra?codteor=1661955\&fi lename=VTS+1+PL718014+\%3D\%3E+PL+7180/2014. Acesso em: 12 out 2016.

BRASIL. RESOLUÇÃO DE 12 DE MARÇO DE 2015 (Conselho Nacional de Combate à Discriminação). Brasília, DF, 2015. Disponível em: https://www.jusbrasil.com.br/diarios/87749317/dou-secao-1-12-03-2015-pg-3. Acesso em: 12 out 2016.

BRASIL, Ministério da Saúde. Conselho Nacional De Combate à Discriminação. Brasil sem homofobia: Programa de Combate à Violência e à Discriminação contra GLBT e de Promoção à Cidadania Homossexual, 2004.

COVIAN, Miguel Rolando. A essência da universidade. Ciência e cultura, v.31, n.6, 1979.

CUNHA, Luiz Antônio. Ensino superior e universidade no Brasil. In: Lopes, E. M. T; Faria Filho, L. M.; Veiga, C. G. (Orgs.). 500 anos de educação no Brasil, $2^{a}$ ed. Belo Horizonte: Autêntica, 2000. p.151-242.

DAVI, Edmar Henrique Dairell; BRUNS, Maria Alves Toledo. Profesoras travestis: trayectorias y experiencias. Revista Intercontinental de Psicología y Educación, México, n. 14 v. 2, 2012. p. 121-142.

FRANCO, Neil; CICILLINI, Graça Aparecida. Professoras trans brasileiras em seu processo de escolarização. Estudos Feministas, v. 23, n. 2, 2015.

JUNQUEIRA, Rogério Diniz. (Org.). Diversidade Sexual na Educação: problematizações sobre homofobia nas escolas, v. 32. Brasília: Ministério da Educação; Unesco, 2009.

LIONÇO, Tatiana; DINIZ, Débora Qual a diversidade sexual dos livros didáticos brasileiros? In: (org.). Homofobia \& Educação: um desafio ao silêncio. Brasília: Letras Livres: EdUnB, 2009.

NARVAZ Martha Giudíce; KOLLER, Sílvia Helena. (2007). A marginalização dos estudos feministas e de gênero na psicologia acadêmica contemporânea. Psico, PUC, v.38, n. 3, 2007. p. 216-223.

SANTOS, Boaventura Souza. A universidade no século XXI: Para uma Reforma Democrática e Emancipatória da Universidade. Educação, Sociedade \& Culturas, n. 23, 2005. p. 137-202.

SEFFNER, Fernando; REIDEL, Marina. Professoras travestis e transexuais: saberes docentes e pedagogia do salto alto. Currículo sem Fronteiras, v. 15, n. 2, 2015. p. 445464.

SOUZA, Heloísa Aparecida; BERNARDO, Márcia Hespanhol. Transexualidade: as consequências do preconceito escolar para a vida profissional. Bagoas, n. 11, 2014. p. 157-175. Disponível em: http://www.periodicos.ufrn.br/bagoas/article/viewFile /6548/5078. Acesso em: 17 jan 2016. 
TORRES Marco Antônio; PRADO, Marco Aurélio. Professoras Transexuais e Travestis no Contexto Escolar: entre estabelecidos e outsiders. Educação \& Realidade, Porto Alegre, v. 39, n. 1, 2014. p. 201-220.

UNESCO. United Nations Educational, Scientific and Cultural Organization. Resposta do Setor de Educação ao bullying homofóbico. Brasília: UNESCO, 2013. 60 p. Disponível em: http://unesdoc.unesco.org/images/0022/002213/221314 por.pdf. Acesso em: 23 set 2017.

VAZ, Henrique Lima. Cultura e Universidade. In: Fávero, M. L. (org.). Educar para a vida. (coleção). Belo Horizonte: Editora Vozes, 1966.

Recebido em Novembro de 2018.

Aprovado em Janeiro de 2019. 